\title{
10 health stories that mattered: Oct. 28-Nov. 1
}

- The federal government will dedicate $\$ 38.1$ million over five years to improve patient safety, announced Health Minister Rona Ambrose. The funding will go to the Canadian Patient Safety Institute, which will lead a new strategy that will initially focus on improving safety in areas such as medications, surgical care, infection control and home care.

- The average wait time after referral for an elective treatment by a specialist increased from 17.7 weeks in 2012 to 18.2 weeks in 2013, according to a report from the Fraser Institute. Wait times decreased, however, in 4 of the 10 provinces surveyed (Ontario, New Brunswick, Nova Scotia and Newfoundland and Labrador).

- Quebec's assisted-suicide bill has "passed an early hurdle in the provincial legislature," reports The Canadian Press. The bill will move on for further study following a successful 84-26 vote.

- Health spending in Canada increased by $2.6 \%$ in 2013 , less than half of the average growth of $7 \%$ seen between 2000 and 2010, reports the Canadian Institute for Health Information. For the first time in 15 years, the rate of growth has not kept pace with inflation and population growth.

- The Public Health Agency of Canada is providing $\$ 500000$ to support a breast health program in Ontario. The money, matched dollar for dollar by the private sector, will go to the Canadian Breast Cancer Foundation (Ontario Region) to promote print, digital and social media approaches to improving breast health.

- The rights of small-scale medical marijuana growers are being infringed by the federal government, according to British Columbia lawyers representing marijuana users and growers, reported The Vancouver Sun. The lawyers have received more than 3000 victim impact statements since the government announced the new Marijuana for Medical Purposes Regulations, which will shift the production and distribution of marijuana from small-scale growers to large commercial farms.

- The Heart and Stroke Foundation's Health Check program came under scrutiny, with an article in The Globe and Mail expressing the concerns of health experts regarding sugary fruit snacks getting a seal of approval. Food items listed in the Health Check program include a strawberry fruit bar with 29 grams of sugar and "mixed-berry bites" with 23 grams of sugar.

- The major employee health risks of concern to employers are sedentary lifestyle, work-related stress, obesity, high blood pressure, smoking, high cholesterol and poor nutrition, according to the 2013 Sun Life-Buffett National Wellness Survey. Barriers to implementing wellness programs to improve employee health include tight budgets, inadequate staffing and inability to quantify results.

- Less than half of both young and senior workers are covered by employer sick leave and disability leave plans, according to the Conference Board of Canada. Other reports recently released by the Conference Board highlighted how much smokers cost their employers because of lost productivity (\$4256 a year) and the need to incorporate nutrition education into school programs.

- About 58000 Ontarians visited emergency departments for dental problems in 2012, reported the Toronto Star. A dental advocacy group, Ontario Oral Health Alliance, cites this as a reason to improve access to dental care for low-income adults. Roger Collier, CMAJ

CMAJ 2013. DOI:10.1503/cmaj.109-4651 